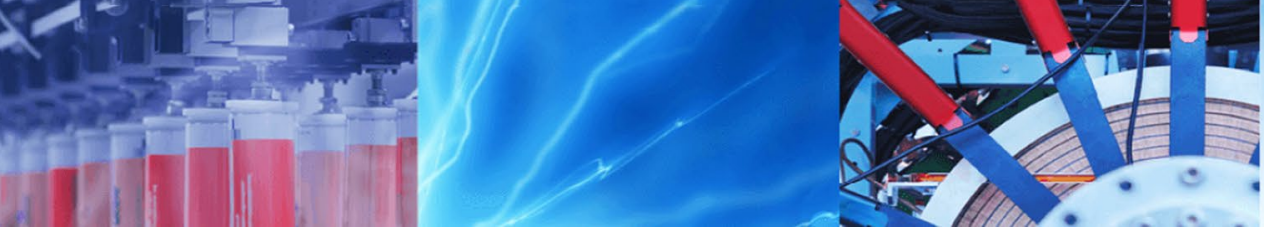

Case Study

\title{
HS2 railway embankment monitoring: effect of soil condition on underground signals
}

\author{
Song Qiu ${ }^{1} \cdot$ Christos Mias $^{1} \cdot$ Weisi Guo ${ }^{1}$ - Xueyu Geng ${ }^{1}$
}

C The Author(s) 2019 OPEN

\begin{abstract}
High speed rail demands precision structural health monitoring in shallow underground environments near embankments. Traditional low frequency wireless channels can communicate with underground sensors, but its large antenna elements are prone to damage from geological stress. In this case study paper, we design a higher frequency compact system and experimentally characterize its performance in-situ, in different soil and moisture conditions that are representative of UK soil conditions near the planned HS2 rail site and weather conditions. Accurate 3D electromagnetic simulation results are also shown to support experimental results and a pathloss model sensitive to soil conditions is developed to inform upcoming high speed rail embankment monitoring deployment. The multi-disciplinary findings presented will also directly inform the depth and data reliability of current high speed rail sensor deployment.
\end{abstract}

Keywords Internet of things · Health monitoring · Railway · Sensor network · Digital twin

\section{Introduction}

Our case study was motivated by the rail network need to continuously monitor railway embankment earth infrastructure, for the risk of serious deformation, due to the increased demand of heavier and faster trains, such as the the UK's planned high-speed rail system (HS2) [1]. The Internet-of-Railway Things (IoRT) is a realistic expectation bring data collection and data science to inform Digital Twin models at national scales [2]. Such monitoring leads to timely interventions, to improve railway safety, based on the analysis of the acquired data [3]. Embankment monitoring is important for ensuring track safety, especially in high-speed rail systems where vibration dynamics can cause a wide range of issues [4], affecting the resilience of the wider multi-modal rail transport network [5]. Traditional monitoring can be achieved through regular human inspection. An alternative is the usage of passenger mobile phone accelerometer sensors [6] but such a crowd-sensing technique lacks data accuracy for proper forecasting and a deeper understanding of the underlying soil mechanics. Remote sensing is another alternative. Its relevant applications areas include: landslide prediction [7], volcano activity monitoring [8], underground tunnel monitoring [9], and commercial sewer structural health monitoring $[10,11]$.

\subsection{Related research}

Avoiding the use of tethered sensors potentially provides more flexibility and reduces maintenance cost. This remote sensing approach of buried transceiver sensor nodes is the subject of this paper. An issue with buried sensors is the effect of the soil's temperature, moisture, texture, and homogeneity on EM wave propagation. The dielectric constant of the soil medium varies as a function of soil texture [12] and behaves as dielectric material composed of air, water and bulk soil [13]. If the soil has small density and high porosity, its constitutive parameters are closer to those of air than when the soil's quantity of water,

$\triangle$ Weisi Guo, weisi.guo@warwick.ac.uk; Song Qiu, song.qiu@warwick.ac.uk; Christos Mias, christos.mias@warwick.ac.uk; Xueyu Geng, xueyu.geng@warwick.ac.uk|'School of Engineering, University of Warwick, Coventry, UK.

SN Applied Sciences (2019) 1:537 | https://doi.org/10.1007/s42452-019-0552-y 
which is measured as volumetric water content (VWC), is relatively high. In the latter case the EM wave attenuates significantly [14]. Besides the VWC, the frequency of the wave influences wireless communication in soil. Related research in $[12,14]$ presented EM wave propagation in soil at around $300 \mathrm{MHz}-1 \mathrm{GHz}$, which reported that the lower the frequency, the less the attenuation. Hence, research aims to identify transceivers of suitable frequency and size, high receiving sensitivity and preferably of low cost.

\subsection{Contributions and organisation}

As a case study paper, the readers benefit by understanding the viability of underground signal propagation in different soil conditions that are representative of high-speed rail embankment monitoring in the West Midland area. The main contributions of this paper are: (1) characterize the potential of underground data transmission using both a prototype $433 \mathrm{MHz}$ RFM69HCW transceiver and CST EM simulation results in a range of representative soil conditions, with different soil mixture components, texture, and moisture values. (2) Developed a linear channel model by repeatedly measuring signal propagation in different soil conditions.

The rest of the case study paper is organized as follows: In Sect. 2, diverse aspects of the experimental setup, such as the underground wireless communication channel, the design of the system, soil texture and VWC and received signal strength are considered. In Sect. 3, the preparation of the experiments is described and the experimental procedures are explained. In Sect. 4, experimental results are presented and analyzed. Finally, the conclusions and future work are included in Sect. 5.

\section{Experimental setup}

The experiment consists of measuring the wireless sensor signal quality in a variety of shallow underground environments that represent embankment placement for HS2.

\subsection{Propagation environment}

Figure 1 illustrates the wireless propagation channel and experimental setup scheme between the buried wireless sensor and a receiver located near the surface. The receiver antenna is buried underneath the boundary of soil and air to potentially minimize the effects of EM wave reflection at the boundary. In order to bury the sensor into the soil and take multiple experiments, we followed the guideline (i.e., tube methodology) provided in [15]: (1) A borehole was dug by a manual rig with a diameter of $5.5 \mathrm{~cm}$, and (2) a plastic tube was provided to support the physical structure

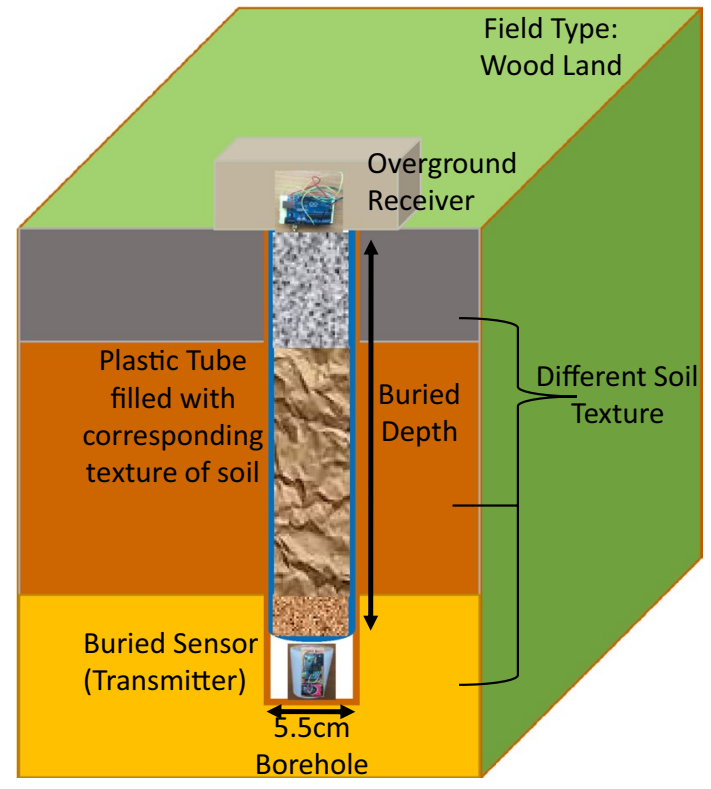

Fig. 1 The illustration of propagation channel and the wireless sensor deployment scheme

of the borehole and was able to fill in different texture or VWC of soil to verify the RSSI performance between sensor and receiver antenna.

\subsection{Communication system prototype}

The transmitter consists 4 key components: (1) sensor, (2) micro controller unit (MCU), (3) radio frequency (RF) unit and (4) power supply. LM35 precision centigrade temperature sensor [16] is used as an example ${ }^{1}$ of sensors, which can be integrated into the transmitter node. Arduino Nano is chosen as the MCU, which is a small, complete, and breadboard-friendly board based on the ATmega328. The RF unit uses the Adafruit RFM69HCW module, which is convenient to be deployed and provides transmission power at $20 \mathrm{dBm}$ at the frequency of $433 \mathrm{MHz}$ based on the legality of using this frequency in the UK. A $9 \mathrm{~V}$ battery is needed to supply power for the circuits. The components of the transmitter are encapsulated into an ABS cylindrical box with $5 \mathrm{~cm}$ in diameter and $10 \mathrm{~cm}$ in height for protection of the transmitter in the soil. The transmitter antenna is one-quarter of the RF wavelength and it is intertwined inside the cylindrical box.

The surface receiver is responsible to receive the sensor data from the underground transmitter. It consists of three key components, the MCU, the RF unit and the

\footnotetext{
1 It is worth noting that the sensor can be replaced by moisture sensor, pore water pressure sensor, acceleration sensor, etc.
} 


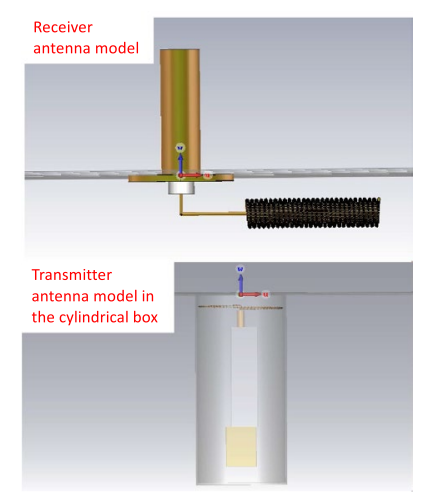

(a) CST built receiver antenna buried in the soil (top) and transmitter encapsulated in the cylindrical box (bottom).

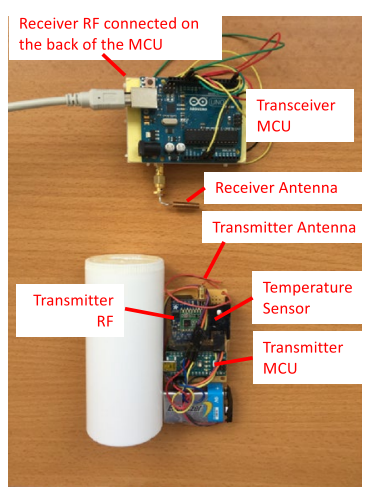

(b) Prototype hardware of reception antenna (top) and transmitter in the cylindrical box (bottom)

Fig. 2 The experimental prototype design shown as a CST simulation model and $\mathbf{b}$ prototype hardware of receiver and transmitter modules

power supply. The MCU used is the Arduino UNO, which is convenient to connect to computer for both data monitoring and power supplying. The RF unit (i.e., receiver RF) is also an RFM69HCW module and has a receiving sensitivity of $-105 \mathrm{dBm}$. The receiving antenna is an unmatched premanufactured un-optimized linear-spiral antenna $(+2 \mathrm{dBi}$ antenna gain). Table 1 summarized the parameters of the components used in the our developed experimental prototype and Fig. 2 shows the simulation model of the prototype built in CST and the hardware we used in the experiment.

\subsection{S-parameter analysis}

Before performing a characterization of the proposed transceiver in soil, a simulation model was developed in CST in order to estimate approximate values of signal strength at the receiver. Simulated $S_{21}$ CST results were obtained in $\mathrm{dB}$ over the range of $300-900 \mathrm{MHz}$ for a depth of $d=100 \mathrm{~cm}$. In the simulation, both dry and a wet soil were considered to match the experimental conditions. Their constitutive parameters were those specified in the CST library. The transmitter and receiver antennas in the CST model were developed to approximately resemble the ones of the experimental kit; hence it is worth noting that the simulation results are only approximate.

The results demonstrate that the proposed transceiver, operating at $433 \mathrm{MHz}$, is suitable for wireless transmission in soil as its receiver sensitivity is well below the receiver values shown in Fig. 3 in our experiments and the anticipated attenuation between dry and wet soil. It is noted that the simulation results are very approximate. In the next section, in-situ experimental results are considered.

\section{Experimental procedures}

\subsection{Site selection and experimental process}

The soils around the testing site were typical UK sandy clay material, with a high water content due to the wet weather from UKs climate. In order to deploy the transmitter into

Table 1 The experimental prototype and components' parameters

\begin{tabular}{lc}
\hline Feature & Parameters and values \\
\hline MCU & Arduino \\
Transmitter MCU & Arduino nano \\
Transceiver MCU & Arduino UNO \\
\hline RF units & Adafruite \\
\hline Transmission band & $433 \mathrm{MHz}$ \\
Transmission power & $+20 \mathrm{dBm}$ \\
Receiver sensitivity & $-105 \mathrm{dBm}$ \\
Receiver antenna gain & $+2 \mathrm{dBi}$ \\
\hline Propagation environment & Plastic box and tube \\
\hline Box diameter & $5 \mathrm{~cm}$ \\
Tube diameter & $5.5 \mathrm{~cm}$ \\
Box thickness & $0.1 \mathrm{~cm}$ \\
Tube thickness & $0.2 \mathrm{~cm}$ \\
Box length & $10 \mathrm{~cm}$ \\
Tube length & Up to $200 \mathrm{~cm}$ \\
\hline
\end{tabular}




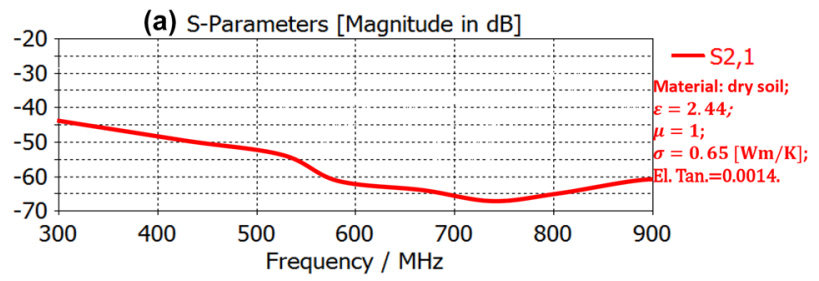

(b) S-Parameters [Magnitude in dB]

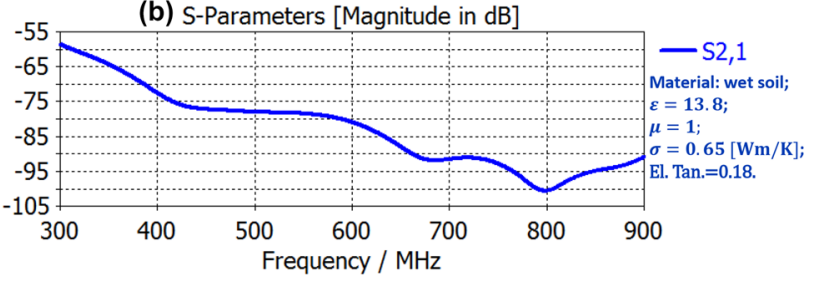

Fig. 3 S-parameter results of S2,1 in a dry soil and $\mathbf{b}$ wet soil

the soil, a hole was dug. Considering the diameter of the transmitter, we used a manual borehole rig to dig a hole in a wood land up to $2 \mathrm{~m}$ in depth. As indicated in [15], manually burying and excavating the transmitter is very time consuming. However, once the hole is dug, a number of sensors with different purposes can be buried. This process was repeated for different soil depth. For experimental efficiency, a plastic tube fully filled with soil was employed, as suggested in [15], incorporating the transmitter and receiver. By varying the length of the plastic tube, it is much easier to excavate the transmitter and take the RSSI measurements (see Sect. 3.3) for different depths.

\subsection{Determination of soil texture and VWC}

During the digging process, it can be observed that the texture of the soil dug out was different at different depths. For example, Fig. 4 illustrates the different soil texture from different depth. As the characteristics of soil have strong impact on the EM propagation, it is necessary to characterize the texture of the soil corresponding to the experiment. The soil texture was analyzed in lab by the jar method and determined according to the soil texture triangle from the portion of sand, silt and clay in the soil sample. In addition to the soil texture, VWC is another necessary parameter to be considered. VWC can be determined by the oven method. VWC is a function of depth [14] and it can be affected by natural environmental factors (e.g., rain, snow). Therefore, we consider two types of VWC, namely, soil texture VWC and overall VWC, where soil texture VWC is the VWC for difference soil texture found in the soil dug out; overall VWC is the VWC of the soil mixtures of all the soil dug out from the hole. Table 2 shows the soil texture at different depth and the relevant VWC.

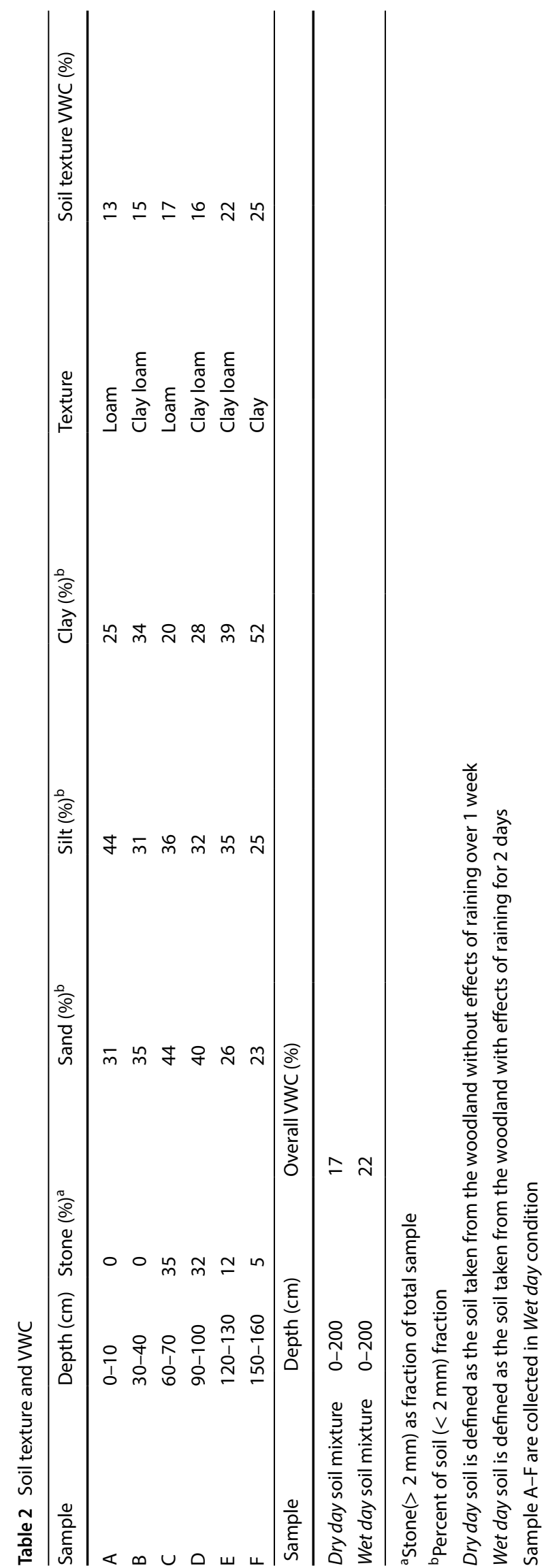




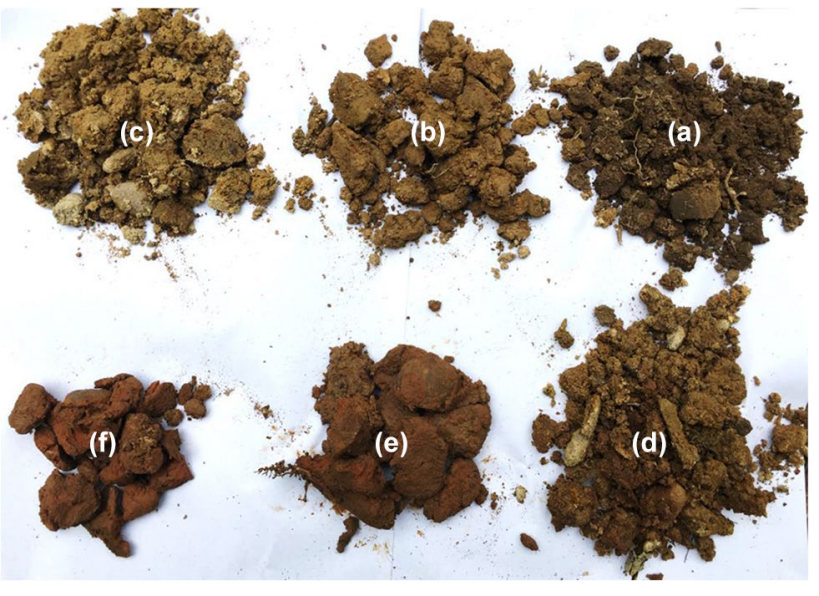

Fig. 4 Soil sample taken from the borehole at different depth: a 0-10 cm, b $30-40 \mathrm{~cm}, \mathbf{c} 60-70 \mathrm{~cm}, \mathbf{d} 90-100 \mathrm{~cm}$, e $120-130 \mathrm{~cm}, \mathbf{f}$ $150-160 \mathrm{~cm}$ respectively

\subsection{RSSI measurement}

This RSSI test identified the transmission quality and signal attenuation in the soil according to the buried depth of sensor and soil conditions. The RF units provide a receiver signal strength indicator (RSSI) measurement. The RSSI measurements were divided into three categories, namely, (1) Tube calibration: the transmitter was placed into a hole in both dry day and wet day conditions at depth of $20 \mathrm{~cm}, 30 \mathrm{~cm}$, $40 \mathrm{~cm}, 50 \mathrm{~cm}$ and $60 \mathrm{~cm}$, respectively. Then RSSI was taken at each depth point with and without deploying the plastic tube filled with soil; (2) reality: the transmitter was placed into the hole initially at depth of $20 \mathrm{~cm}$, and the depth was increased in steps of $20 \mathrm{~cm}$ until the wireless connection lost (RSSI below receiver sensitivity). The plastic tube was deployed filled soil from different depths to create the real soil environment; (3) Texture: the transmitter was placed into the hole initially at depth of $20 \mathrm{~cm}$, and the depth was increased in steps of $20 \mathrm{~cm}$ until the wireless connection lost. The plastic tube was filled with only one of the textures of soil found in Fig. 4 (loam, clay loam and clay respectively) in the plastic tube. In Table 3, the RSSI value at each depth is the average of 200 measurements.

\section{Results and analysis}

In this section, the robustness of RSSI performance of our developed experimental prototype is considered. Firstly, the plastic tube is used. The presence of the plastic tube is expected to affect the results. Hence, the impact of its presence is examined. Secondly, the path loss caused by soil is examined with respect to VWC and soil texture to show the reliability of our prototype. Table 3 summarises the RSSI results (without plastic tube calibration) of the three RSSI experimental categorises and shows the significant propagation results for consideration.

\subsection{Calibration of plastic tube}

We consider the RSSI with the plastic tube and without the plastic tube denoted as $P_{\mathrm{u}}$ and $P_{\mathrm{nu}}$ in $\mathrm{dBm}$, respectively. The path loss caused by the plastic tube is $L_{\mathrm{pt}}$ in $\mathrm{dB}$, given as,

$L_{\mathrm{pt}}=P_{\mathrm{nu}}-P_{\mathrm{u}}$

Table 3 Summarised results RSSI data (without calibration): mean value from 200 independent test batches with (standard deviation)

\begin{tabular}{|c|c|c|c|c|c|c|c|c|c|c|}
\hline Tube calibration & RSSI at: $20 \mathrm{~cm}$ & $30 \mathrm{~cm}$ & $40 \mathrm{~cm}$ & $50 \mathrm{~cm}$ & $60 \mathrm{~cm}$ & & & & & \\
\hline Dry day without tube & $\begin{array}{l}-48.14 \\
(0.22)\end{array}$ & $\begin{array}{l}-49.10 \\
(0.15)\end{array}$ & $\begin{array}{l}-50.04 \\
(0.17)\end{array}$ & $\begin{array}{l}-54.33 \\
(0.25)\end{array}$ & $\begin{array}{l}-58.53 \\
(0.32)\end{array}$ & & & & & \\
\hline Wet day without tube & $\begin{array}{l}-49.19 \\
(0.23)\end{array}$ & $\begin{array}{l}-51.10 \\
(0.31)\end{array}$ & $\begin{array}{l}-52.91 \\
(0.28)\end{array}$ & $\begin{array}{l}-55.37 \\
(0.41)\end{array}$ & $\begin{array}{l}-58.39 \\
(0.49)\end{array}$ & & & & & \\
\hline Reality & RSSI at: $20 \mathrm{~cm}$ & $40 \mathrm{~cm}$ & $60 \mathrm{~cm}$ & $80 \mathrm{~cm}$ & $100 \mathrm{~cm}$ & $120 \mathrm{~cm}$ & $133 \mathrm{~cm}$ & $140 \mathrm{~cm}$ & & \\
\hline Dry day with tube & $\begin{array}{l}-50.99 \\
(0.27)\end{array}$ & $\begin{array}{l}-53.10 \\
(0.37)\end{array}$ & $\begin{array}{l}-62.06 \\
(0.23)\end{array}$ & $\begin{array}{l}-72.98 \\
0.41\end{array}$ & $\begin{array}{l}-82.98 \\
(0.33)\end{array}$ & $\begin{array}{l}-97.06 \\
(0.36)\end{array}$ & & $\begin{array}{l}-104.92 \\
(0.36)\end{array}$ & & \\
\hline Wet day with tube & $\begin{array}{l}-51.98 \\
(0.24)\end{array}$ & $\begin{array}{l}-56.04 \\
(0.24)\end{array}$ & $\begin{array}{l}-63.83 \\
(0.51)\end{array}$ & $\begin{array}{l}-73.78 \\
(0.58)\end{array}$ & $\begin{array}{l}-85.99 \\
(0.61)\end{array}$ & $\begin{array}{l}-98.85 \\
(0.72)\end{array}$ & $\begin{array}{l}-104.83 \\
(0.52)\end{array}$ & & & \\
\hline Texture & RSSI at: $20 \mathrm{~cm}$ & $40 \mathrm{~cm}$ & $60 \mathrm{~cm}$ & $80 \mathrm{~cm}$ & $93 \mathrm{~cm}$ & $100 \mathrm{~cm}$ & $110 \mathrm{~cm}$ & $120 \mathrm{~cm}$ & $140 \mathrm{~cm}$ & $145 \mathrm{~cm}$ \\
\hline Loam & $\begin{array}{l}-50.00 \\
(0.27)\end{array}$ & $\begin{array}{l}-52.98 \\
(0.29)\end{array}$ & $\begin{array}{l}-59.02 \\
(0.23)\end{array}$ & $\begin{array}{l}-68.00 \\
(0.32)\end{array}$ & & $\begin{array}{l}-79.01 \\
(0.25)\end{array}$ & & $\begin{array}{l}-89.99 \\
(0.38)\end{array}$ & $\begin{array}{l}-103.92 \\
(0.34)\end{array}$ & $\begin{array}{l}-104.96 \\
(0.19)\end{array}$ \\
\hline Clay loam & $\begin{array}{l}-51.90 \\
(0.39)\end{array}$ & $\begin{array}{l}-55.98 \\
(0.24)\end{array}$ & $\begin{array}{l}-68.94 \\
(0.25)\end{array}$ & $\begin{array}{l}-80.11 \\
(0.41)\end{array}$ & & $\begin{array}{l}-98.94 \\
(0.33)\end{array}$ & $\begin{array}{l}-104.95 \\
(0.23)\end{array}$ & & & \\
\hline Clay & $\begin{array}{l}-60.12 \\
(0.43)\end{array}$ & $\begin{array}{l}-69.07 \\
(0.45)\end{array}$ & $\begin{array}{l}-81.07 \\
(0.45)\end{array}$ & $\begin{array}{l}-99.01 \\
(0.25)\end{array}$ & $\begin{array}{l}-104.94 \\
(0.30)\end{array}$ & & & & & \\
\hline
\end{tabular}


(a)

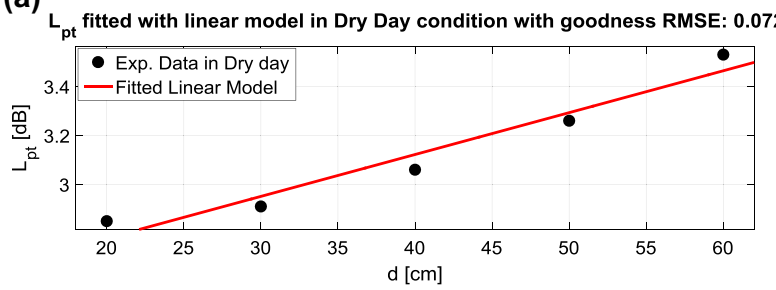

(b)

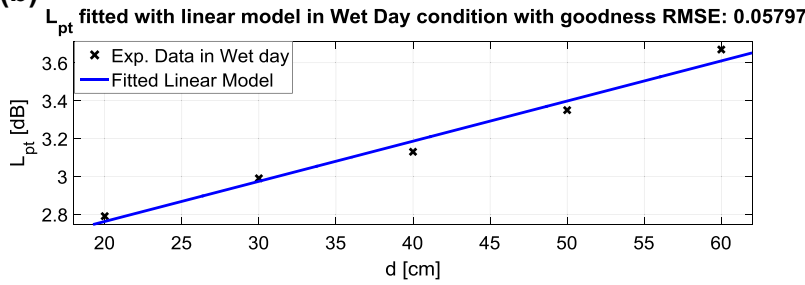

Fig. 5 The plot of $L_{\mathrm{pt}}$ as a function of distance in $\mathbf{a}$ dry day and $\mathbf{b}$ wet day, fitted by linear models

Thus, $L_{\mathrm{pt}}$ can be statistically found from Table 3 with respect of distance. We plot the $L_{\mathrm{pt}}$ versus distance in Fig. 5 and show the $L_{\mathrm{pt}}$ can be fitted as a linear model in both dry day and wet day conditions, given as,

$L_{\mathrm{pt}}=a_{1} d+a_{2}$

where $d$ is the transmission distance in $[\mathrm{cm}], a_{1}$ is the rate of linear model given as,

$a_{1}=\left\{\begin{array}{l}0.017 \mathrm{~dB} / \mathrm{cm} \text { Dry day } \\ 0.021 \mathrm{~dB} / \mathrm{cm} \text { Wet day }\end{array}\right.$,

and $a_{2}$ is the model constant given as .

$a_{2}=\left\{\begin{array}{l}2.438 \mathrm{~dB} \text { Dry day } \\ 2.338 \mathrm{~dB} \text { Wet day }\end{array}\right.$.

It is worth noting that the tube used for ease of experiment did not cause significant signal attenuation and the loss is similar in the soil of both dry day and wet day conditions according to Fig. 5 and the parameters in Eqs. 3 and 4. This was anticipated from the fact that the overall VWC values for those days were similar.

\subsection{Analysis of path loss in soil}

\subsubsection{The effect of VWC}

Figure 6 shows the effect of VWC on RSSI. Based on the plastic tube calibration, we show the calibrated RSSI in Fig. 6 as a function of the buried depth. It can be predicted that the maximum transmission distance for the transmitter in the dry day soil and wet day soil could be approximately $145 \mathrm{~cm}$ and $140 \mathrm{~cm}$ respectively. Particularly,

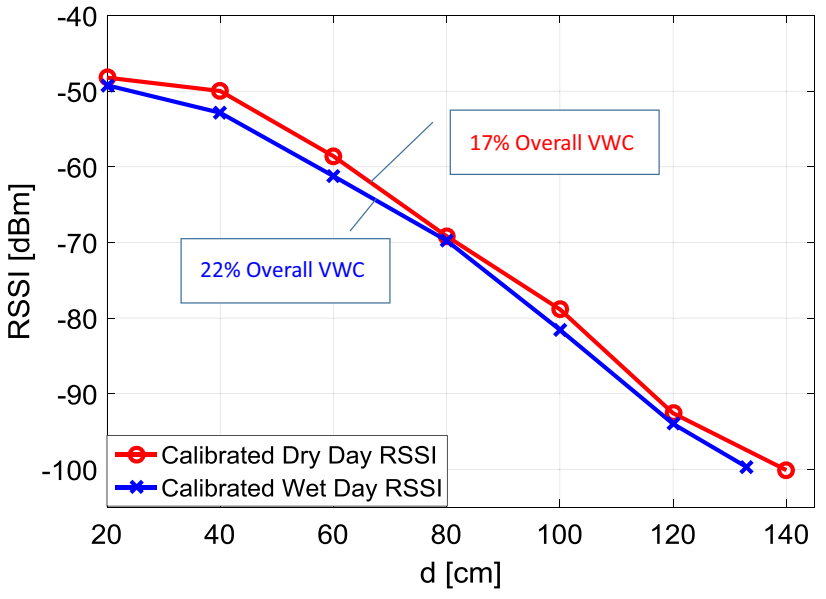

Fig. 6 The effect of VWC on RSSI as a function of distance

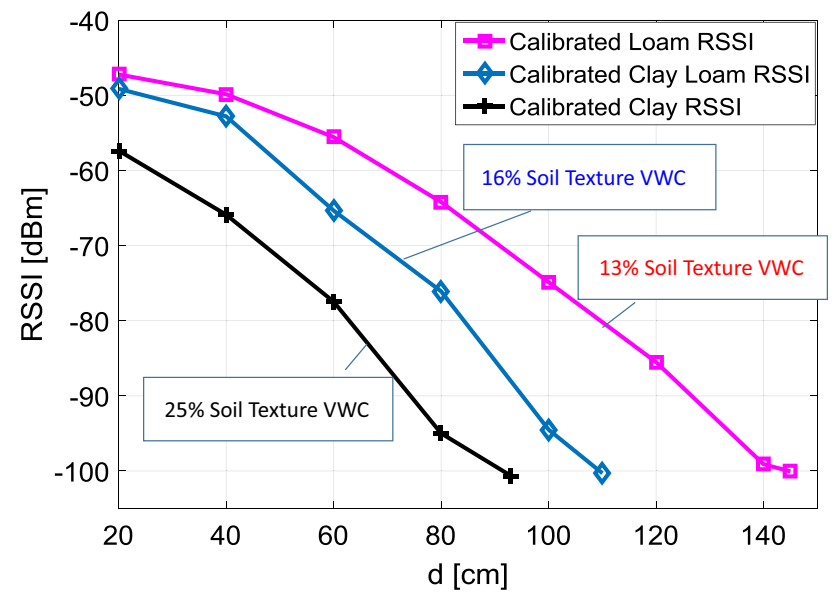

Fig. 7 The effect of soil texture on RSSI as a function of distance

according to the RSSI measurements in reality category in Table 3, it can be observed that the average of standard deviation of RSSI on wet day (0.49) is approximately 1.5 times higher than dry day (0.33). Hence a higher VWC not only reduces transmission signal but affect the received signal variation.

\subsubsection{The effect of soil texture}

Figure 7 shows the effect of soil texture on RSSI. It can be observed that the clay with highest VWC significantly reduces the RSSI over distance. Consider the calibrated RSSI values, at depth of $80 \mathrm{~cm}$, the RSSI of clay approximately suffers $20 \mathrm{~dB}$ power loss compared to clay loam and $32 \mathrm{~dB}$ to loam texture. The results reveal an important fact that when deploying the transmitter in soil, it is essential to consider the soil texture at the corresponding depth as the soil texture will affect the performance significantly. For example, London clay is a stiff bluish clay, widely 
discovered in the underground of southeast of England and its thickness can be up to $150 \mathrm{~m}$ [17]. The transmission distance will be limited within $1 \mathrm{~m}$ in the London clay texture based on Fig. 7. If the transmitter is intended to be buried into such places at a large depth (e.g., $5 \mathrm{~m}$ ), additional transceivers need to be deployed to act as repeaters and ensure the data transmission.

\section{Conclusions}

In this case study, we experimentally and simulate the viability of underground signal propagation in different soil conditions that are representative of high-speed rail (HS2) embankment monitoring in the West Midland area. We employ a $433 \mathrm{MHz}$ transceiver as an example of low-cost high-sensitivity buried wireless sensor node for railway embankment earth infrastructure monitoring. For the first time, a series of experiments were carried out to understand the impact of moisture and soil composition on wireless signal propagation for the soil environment near planned HS2 deployment. S-parameter 3D electromagnetic simulation results are used to validate results and improve the design. Future work will be focused on (1) transmitter and receiver antenna optimization, and (2) conducting experiments with repeaters for increasing EM wave propagation distance in soil.

Acknowledgements This research is supported by University of Warwick Research Development Fund (RDF), EC H2020 MSCA-RISE Grant 778360-HERCULES and 778305-DAWN4IoE.

\section{Compliance with ethical standards}

Conflict of interest The authors declare that they have no conflict of interest.

Open Access This article is distributed under the terms of the Creative Commons Attribution 4.0 International License (http://creativeco mmons.org/licenses/by/4.0/), which permits unrestricted use, distribution, and reproduction in any medium, provided you give appropriate credit to the original author(s) and the source, provide a link to the Creative Commons license, and indicate if changes were made.

\section{References}

1. HS2 (2012) Summary of effects of HS2 London to West Midlands route refinements. Crown
2. National Infrastructure Commission (2017) Data for the public good

3. Jo O, Kim Y, Kim J (2018) Internet of things for smart railway: feasibility and applications. IEEE Internet Things J 5(2):482-490

4. Geng X, Lv S, Liu G, Hu Q (2009) Analysis of the settlement of a railway track caused by track-ground vibration on a poroelastic half-space. In: 4th international symposium on environmental vibrations: prediction, monitoring, mitigation and evaluation, 1

5. Pagani A, Mosquera G, Alturki A, Johnson S, Jarvis S, Wilson A, Guo W, Varga L (2019) Resilience or robustness: identifying topological vulnerabilities in rail networks. R Soc Open Sci 6:181301

6. Hodge V, O'Keefe S, Weeks M, Moulds A (2015) Wireless sensor networks for condition monitoring in the railway industry: a survey. IEEE Trans Intell Transp Syst 16:1088-1106

7. Sheth A, Thekkath C, Mehta P, Tejaswi K, Parekh C, Singh T, Desai U, Bombay I (2005) Senslide: a sensor network based landslide prediction system. SenSys. https://doi.org/10.1145/10989 18.1098954

8. Werner-Allen G, Marcillo O, Johnson J, Ruiz M, Lees J (2006) Deploying a wireless sensor network on an active volcano. IEEE Internet Comput 10(2):18-25

9. Bennett P, Soga K, Wassell I, Fidler P, Abe K, Kobayashi Y, Vanicek $M$ (2010) Wireless sensor networks for underground railway applications: case studies in Prague and London. Smart Struct Syst 6:619-639

10. Paek J, Chintalapudi K, Govindan R, Masri S (2005) A wireless sensor network for structural health monitoring: performance and experience. In: IEEE workshop on embedded networked sensors (EmNetS-II)

11. Elkmann N, Althoff H, Kutzner S, Stuerze T, Saenz J, Reimann B (2007) Development of fully automatic inspection systems for large underground concrete pipes partially filled with wastewater. In: IEEE international conference on robotics and automation, pp 130-135

12. Peplinski N, Ulaby F, Dobson M (1995) Dielectric properties of soils in the $0.3-1.3 \mathrm{GHz}$ range. IEEE Trans Geosci Remote Sens 33(3):803-807

13. Vuran M, Silva A (2010) Communication through soil in wireless underground sensor networks theory and practice. In: Ferrari $G$ (ed) Sensor network. Springer, Berlin, pp 309-347

14. Li L, Vuran MC, Akyildiz IF (2007) Effects of soil physical properties on GPR for landmine detection characteristics of underground channel for wireless underground sensor networks. In: Med-Hoc-Net

15. Silva A, Vuran M (2010) Development of a testbed for wireless underground sensor networks. EURASIP J Wirel Commun Netw 20(1):20-30

16. Texas (2016) LM35 precision centigrade temperature sensors data sheet. Texas Instrument Ltd.

17. Sumbler M (1996) London and the Thames Valley. British regional geology series, British Geological Survey

Publisher's Note Springer Nature remains neutral with regard to jurisdictional claims in published maps and institutional affiliations. 